\title{
Reverse engineering of research engine cylinder-head
}

ARTICLE INFO

Received: 16 September 2021

Revised: 27 October 2021

Accepted: 29 October 2021

Available online: 2 November 2021
The pursuit of increasing the efficiency of internal combustion engines is an ongoing engineering task that requires numerous research efforts. New concepts of injection or combustion systems require preliminary investigation work using research engines. These engines, usually single-cylinder, make it possible to isolate a single variable in a complex combustion mixture preparation process, thus enabling analysis of the changes being made. However, these engines are relatively expensive and their designs are offered by a limited number of manufacturers. The authors of this paper have successfully undertaken the engineering task of modifying an existing research engine cylinder head in such a way as to implement an electronically controlled variable valve timing system of the intake system. The process of reverse engineering, together with design assumptions that finally contributed to the construction of the assumed solution has been described in this paper.

Key words: reverse engineering, research engine, 3D measuring system, tomographic measurement, variable valve timing

This is an open access article under the CC BY license (http://creativecommons.org/licenses/BY/4.0/)

\section{Introduction}

Human activity towards continuous economic development causes, among others, a significant expansion of the transportation network across the planet. Despite the passage of decades, the primary source of mechanical energy is still constituted by various types of internal combustion engines (ICEs), which are estimated to be approximately 2 billion in total worldwide [1]. Restrictions applied to internal combustion engines, which are the dominant source of propulsion, resulting in a preference for alternative propulsion systems. Considering the size of the ICE share, it is difficult to talk about a complete shift away from this type of energy source in support of battery electric vehicles. Additionally, no solution could replace ICE in such a wide range as Automotive, Marine, Aviation or Electric production. Increased research on combustion systems and exhaust gas aftertreatment systems applied in many solutions implemented in series production, resulting in a significant rise in energy conversion efficiency and reduction of toxic emissions. The mentioned effect led to an improvement in the attractiveness of ICE and a significant reduction in its environmental impact [2].

The outlook for further development of internal combustion engines based on the automotive industry is related to the necessity of meeting future emission standards, especially $\mathrm{CO}_{2}$ limits $[3,4]$. In order to meet future standards, efforts are being made, leading to the electrification of powertrains. Parallel work is being carried out to improve the ICE. Figure 1 shows the evolution of the propulsion system, whose priority in the initial phase of development was low cost and high reliability (ICE 1.0) to technologically advanced hybrid systems (ICE 4.0) based on the close cooperation of the internal combustion engine with the electric system [5].

Developing an internal combustion engine involves the experimental research carried out on model test stands such as constant volume chambers or rapid compression machines and real single or multi-cylinder engines [6]. The process of a hierarchical approach to engine testing pre- sented by Kyrtatos et al. [7] combines the analysis of fundamental aspects and the application of the tested technical solution in a closed application-fundamentals-application cycle. For this purpose, simulations and experiments performed with modern tools are used. The experimental part includes the study of fundamental phenomena carried out using a constant volume chamber with optical access, optical testing on a single cycle RCEM machine using assumed geometry and finally on a single cylinder research engine close to the production engine.

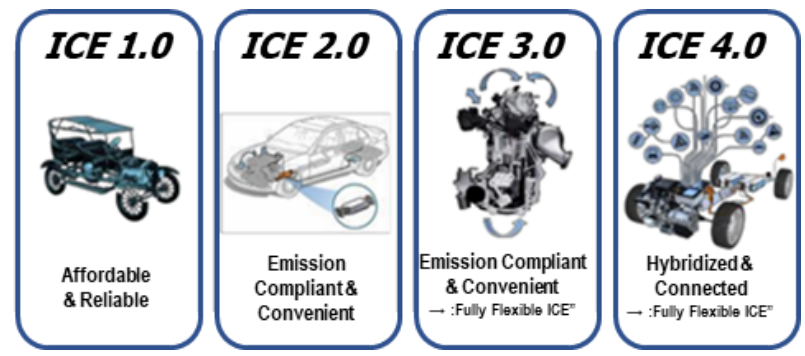

Fig. 1. Passenger car powertrain system development [5]

The engine research results are the implementation of new highly advanced systems that reduce fuel consumption, which translates directly into lower GHG emissions [8]. Engine manufacturers indicate the possibility of fuel efficiency improvement in the range of $20-30 \%$ by implementing, e.g. variable compression ratio VCR, cylinder deactivation or application of unconventional work cycles of Atkinson/Miller engine in the hybrid drive system. Also, the combustion of lean mixtures, decreasing the combustion temperature, and spark-assisted compression ignition system are attractive [9].

The introduction of a new solution to large-scale production is a complex process requiring considerable time and financial resources. Figure 2 presents the state of advancement of selected systems for increasing the efficiency of an internal combustion engine. It is worth noting that there are systems not introduced to mass production (Full 
Authority Cylinder Deactivation) and those commonly used (Variable Valve Timing). The continuous modernization of ICE requires new test benches or upgrades to existing ones. Hence the need to take into account in the development of further improvements, e.g. the presence of variable valve timing.

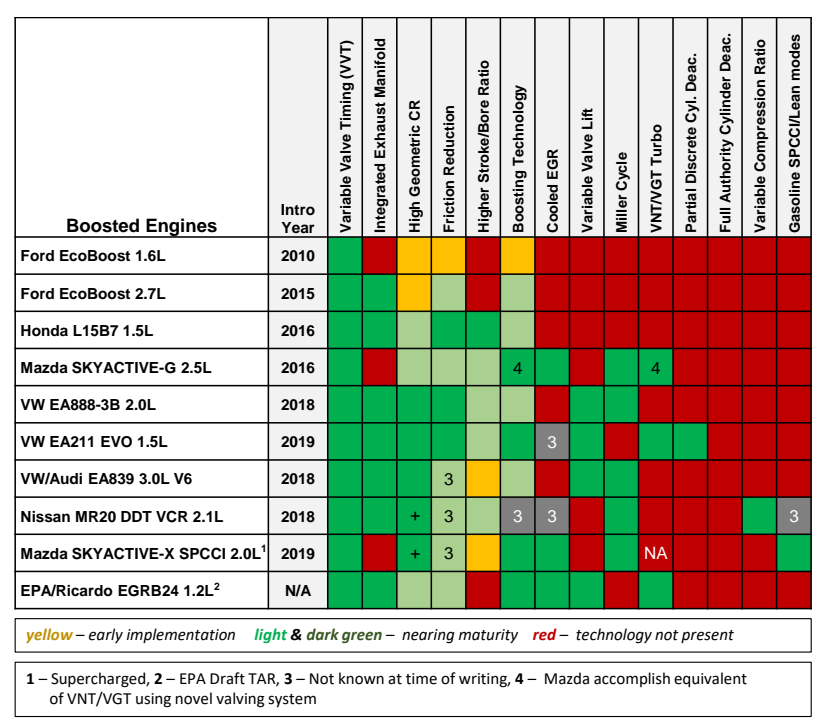

Fig. 2. Combustion engines technology upgrades and implementation status [10]

The Institute of Combustion Engines and Powertrains of Poznan University of Technology has a single-cylinder research engine AVL 5804, part of a dynamometer bench. It allows for advanced development work in the field of mixture formation and combustion systems. Due to its high operational value, this test stand is subject to the continuous modernization in line with current trends. Originally the engine worked as a diesel with a direct fuel injection system based on an electronic rotary distributor pump. Subsequently, it was modified in several ways, including applying the common rail system and system for co-combustion of liquid and gaseous fuels (dual fuel). Finally, the design in which the spark-jet ignition system (TJI) was applied and was introduced for using gaseous fuels [11-13].

\section{Main goal of the project}

The desire to conduct further research related to the development of low-emission combustion systems forced us to carry out another significant modification of the engine head construction so that it was possible to implement a smooth change of intake camshaft position in relation to the crankshaft position. In order to do so, a new head with a modified construction was made, in which an electrically controlled variable valve timing system was implemented.

For that purpose it was decided to implement the reverse engineering method while a new cylinder head with adequate variable valve timing was at that time neither available nor financially essential. For casting of the new and adequately modified cylinder head the knowledge of the internal structure and geometry was essential as well. To achieve the appropriate geometric mapping the 3Dscanning technology has been implemented and on this way the full 3D-project has been generated. It was the basis for casting, modifications and final turning and milling post processing.

The production process of the new cylinder-head, including the design, manufacture and start-up phases has been presented in this paper.

\section{Features and significant of Research engines}

In the development of internal combustion engines, it is essential to carry out experiments on test benches that reproduce the real engine's continuous operation as closely as possible. For this purpose, single or multi-cylinder experimental engines are used (Fig. 3). The use of TSCE engines is particularly attractive due to the possibility of analyzing the basic engine systems and processes during operation from cycle to cycle. Compared to multi-cylinder MCE engines, single-cylinder TSCEs reduce the cost of test equipment and greatly increase diagnostic availability. Single cylinder TSCE and OSCE engines are currently widely used for primary research types. For development projects, the implementation of single cylinder engines must be carefully considered [14].

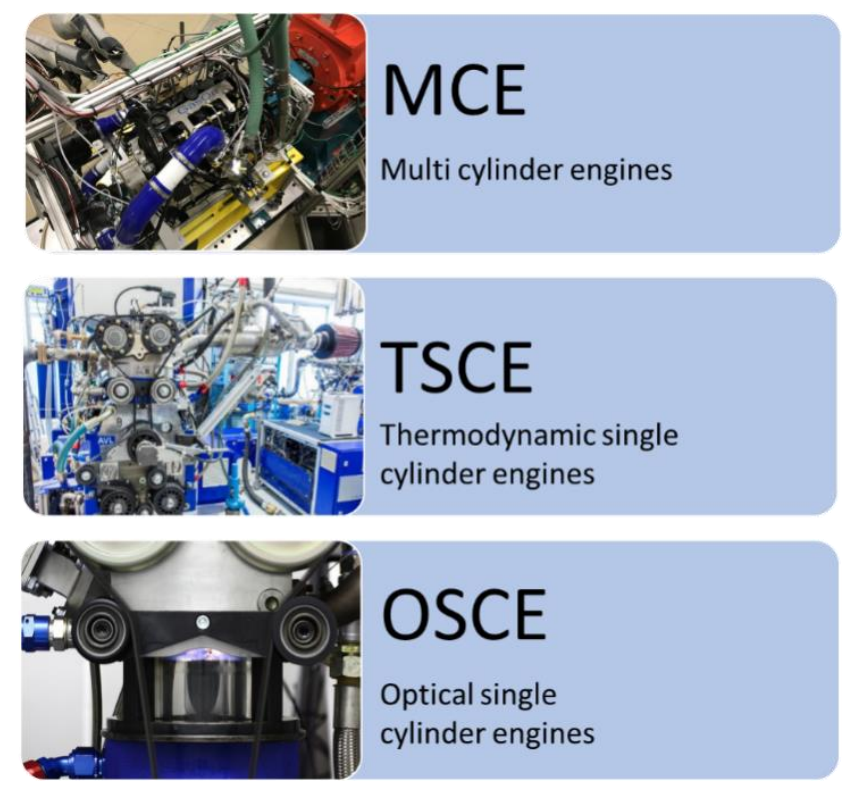

Fig. 3. Research engines types [14, 22, 32, 33]

Single cylinder optical engines are engines constructed to allow optical access to the working volume. The beginnings of implementing optical research on a running engine dates to 1920's and early 1930's [15]. The breakthrough came in 1961 when Bowditch [16] published a new design of research engine, assuming optical access through the crown of a specially designed expanded piston. This concept was initiated with the implementation of overhead valve engines and is still being developed today.

The advantage of using optical engines is the possibility of visualising in-cylinder processes using advanced measurement techniques [15]. It is particularly applicable in validating CFD models and exploring the knowledge of charge movement, combustion, and combustion product formation. However, it is worth noting the requirements for optical access design. For laser methods, at least two sight glasses are required. 
Although optical engines have some advantages, they have significant limitations in terms of speed and load. The use of a transparent cylinder, most often made of quartz or sapphire, substantially affects the design of the pistoncylinder gasket. Unconventional sealing systems made of polyamide or graphite are used for this purpose. As a result, it is possible to eliminate a lubricating medium that adversely affects the quality of the obtained image. In addition, modification of the piston design involves additional mass, significantly increasing the inertia forces [17].

Johansson et al. [18] when carrying out a study on the effect of supercharging on the combustion and emissions of SGDI engine, used fully transparent optical engine and TSCE also called full metal engine with a displacement of $475 \mathrm{~cm}^{3}$. The tests were conducted at 5 points with a maximum engine speed of $2000 \mathrm{rpm}$ and a load of 4 bar BMEP. A problem was observed in the use of the optical engine due to the impossibility of obtaining steady-state conditions because of the short time available for adjusting the control parameters. The mentioned engine should be operated for a short time to minimize the risk of mechanical damage. Therefore, the advantages of both engines were combined, and TSCE engine was used for emission measurements and the OSCE engine for visualization of the combustion process.

In another study [19], a light-duty full metal engine was compared with an optical engine allowing optical access to the combustion chamber from the piston crown side under the same operating conditions. In these studies, special attention was paid to the thermodynamic aspect related to the significant differences in thermal conductivity of the materials used [20]. The results indicate a significant effect of using different materials on the heat flow characteristics. Measurements of the piston bottom temperature near the TDC by laser-induced phosphorescence indicate about $110^{\circ} \mathrm{C}$ higher temperature for the optical piston at 2 bar IMEP. Differences in the thermal state of the system result in different thermodynamic parameters in the cylinder. The authors point out the requirement to control the thermodynamic state of the combustion chamber walls to increase the convergence of results with full metal engines.

The considerable difficulties associated with the use of optical engines have resulted in thermodynamic engines in a wide range of applications. Current commercial sales of single cylinder research engines, among others, include AVL, Ricardo and FEV. AVL points to developing benches equipped with large single cylinder research engines in a modular approach that provides great flexibility. Outlining four basic platforms allow for engines with cylinder diameters of 150-520 mm [21]. In terms of smaller engines [22] three series are offered: 540 dedicated to passenger cars, 580 for Light duty engines and 530 for heavy duty engines. Ricardo, on the other hand, offers four engine types for different purposes [23]. Starting with the Hydra model for passenger car applications, the Proteus 300 for HD engines, the Atlas II for marine off-highway and power generation applications, and the last one, the Prometheus, with a piston diameter of 200-300 $\mathrm{mm}$ and maximum stroke of $1500 \mathrm{~mm}$. FEV also offers designs with a wide range of cylinder diameters (65 to $530 \mathrm{~mm}$ ) [24].
A relatively easy way to modify the single cylinder research engine that this paper uses is an effective tool for advanced engine research [25]. For example, for the study of knocking combustion phenomena, an AVL 5402 research engine originally operating as CI mode with a centrally located injector was modified. As a result, the engine was converted to SI mode with a PFI injection system and a circular ring was placed under the cylinder head equipped with four spark plugs and four pressure sensors mounted radially [26]. Subsequently, the Ricardo Hydra engine was modified for HCCI Combustion. This research used rebreathe style camshaft, piston coating and heat flux probes assembled in cylinder head [27]. Grabner et al. redesigned the AVL 5403 engine to compare two central and side injector placement positions during E85 and gasoline combustion [28]. It is also popular to modify research engines to burn gaseous fuels in a mono fuel or dual fuel configuration $[29,30]$.

\section{Modernization concept}

The primary responsibility for proper engine operation is the charge exchange system, i.e. intake and exhaust valve lift and timing. Proper control of the opening/closing of the inlet and exhaust system directly influences the internal combustion engine parameters such as power, torque, fuel consumption, and exhaust emissions. The first systems enabling optimization of the charge exchange process were developed in the early 1980s. Subsequent generations of these systems have concerned the use of both inlet and outlet valve opening control.

In this project it was decided to use a less popular system of variable valve timing control, which is used in Lexus vehicles. In order to implement variable intake valve timing in a single-cylinder research engine, an electric motor with a $\pm 20^{\circ}$ control range (total control range is $40^{\circ}$ ) was implemented. The VVT-iE (Variable Valve Timing-intelligent Electric) system allows smooth adjustment of the inlet valve opening using only an electric signal for control. The use of an electric motor (instead of a hydraulic or mechanical system) allows the system to operate effectively both at low temperatures and at low engine speeds with low oil pressure. The adopted Lexus solution uses a second generation actuator combined with a planetary gearbox (Fig. 4).

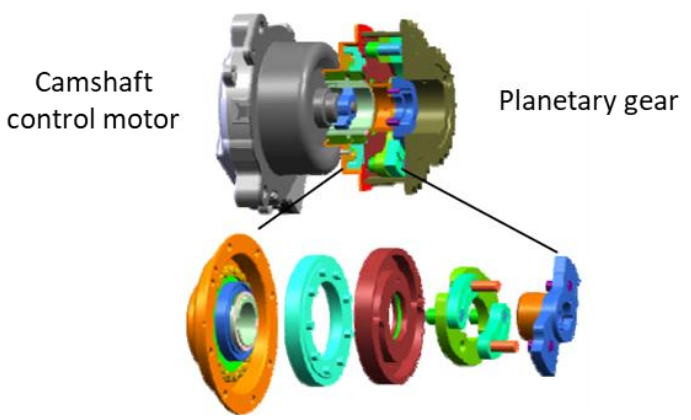

Fig. 4. Elements of the applied variable phase execution system [31]

An additional advantage of using electrical variable camshaft phasing control is the relatively small upgrade to the current timing system of the test engine. The scheme of acceleration and deceleration of the timing phases in the applied system is shown in Fig. 5. 


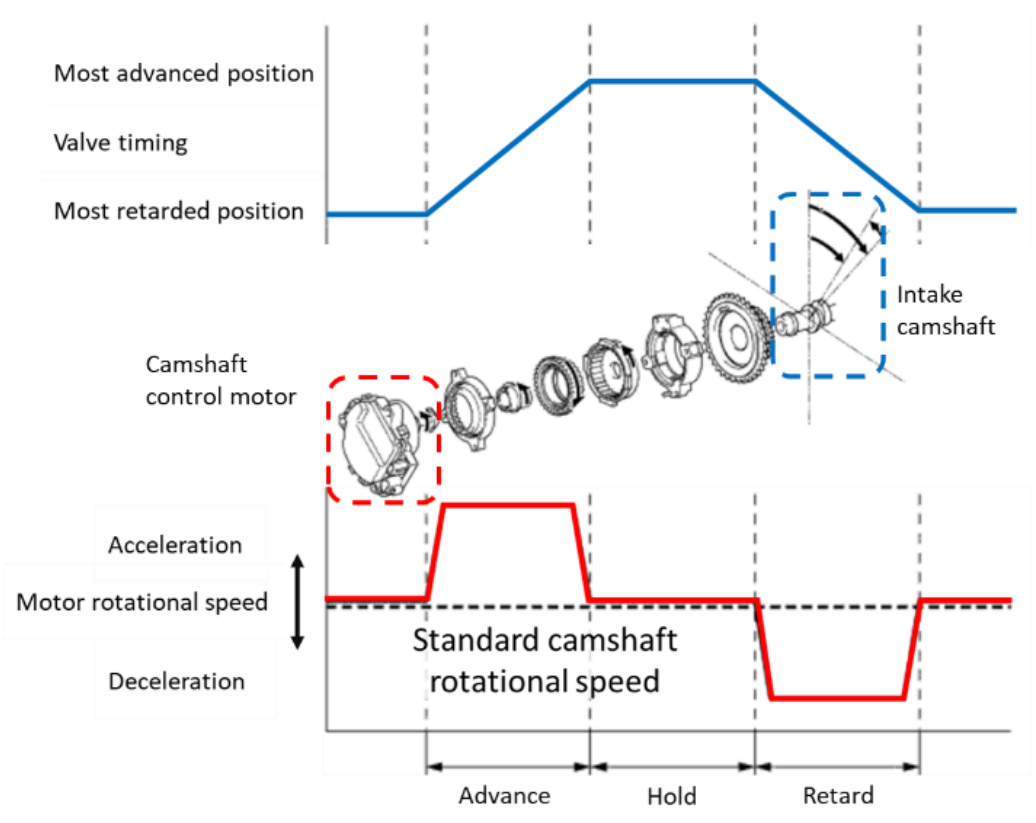

Fig. 5. Relationship between electric motor speed and advance and retard timing [34]

The camshaft control motor consists of a motor that operates the camshaft control actuator in the advance or retard direction, an EDU that controls the rotational condition of the motor and a Hall IC type rotational sensor that detects the current shaft speed. The motor is a brushless type DC motor installed in the engine front cover in front of the camshaft control actuator. The axis of the electric motor coincides with the axis of the intake shaft (Fig. 5). In accordance with the target intake shaft position, the ECM transmits the motor rotational speed instruction signals and the motor rotational direction instruction signals to the EDU. The EDU drives the motor to rotate the intake camshaft in advance or retard direction based on these signals. To advance, the electric motor speed becomes faster than the camshaft speed. To retard, the motor rotational speed becomes slower than the camshaft rotational speed. Depending on the operating condition of the internal combustion engine, the electric motor can operate in two directions. As the advance signals from the ECM cause the motor to operate at a higher speed than the camshaft, the camshaft gear rotates in the direction shown in the illustration via the reduction unit. This rotation causes the intake camshaft coupled with the camshaft gear to rotate in the advanced direction. As the retard signals from the ECM cause the motor to run slower than the camshaft, the camshaft gear rotates in the direction shown in the illustration via the reduction unit. This rotation causes the intake camshaft coupled with the camshaft gear to rotate in the retard direction.

The ability to independently control the timing phases using an electric motor creates opportunities for new research on the presented experimental engine.

\section{Recovery of OEM cylinder head geometry}

\subsection{Optical scanning}

Due to the modernization of the research engine in operation, it was necessary to make a $3 \mathrm{D}$ model of the research engine cylinder head equipped with a spark jet ignition system $[35,36]$ using only non-destructive methods. Therefore, two non-contact measurement methods were used. The first stage consisted of optical scanning of the outer planes using the ATOS II Triple Scan measurement system. Due to its accuracy and versatility, this system is used in industry and scientific institutions [37]. Using the laser triangulation method (used in the discussed cylinder-head reconstruction method), the measuring system consists of a laser light source displayed as a line, the measuring object, and a camera as a photosensitive element. Working with an overhead projector, stereoscopic cameras capture three views of an object within a single measurement. This technology requires fewer scans, providing higher quality data even when scanning shiny surfaces or complex geometric figures. Optical scans were realized both for the manufactured test engine cylinder head and the individual components mounted in the system (Fig. 6 and 7) and the location of the cylinder head on the engine (Fig. 8).

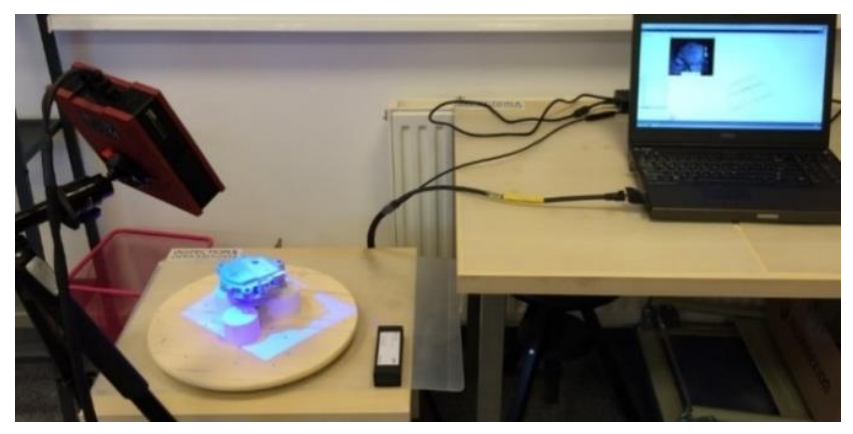

Fig. 6. Optical scanning process of an camshaft control motor using GOM's ATOS Core

The ATOS measuring system uses the measurement and projection method developed by Gesellschaft für Optische Messtechnik (GOM). The use of blue light technology makes it possible to carry out measurements regardless of 
the lighting conditions. The two CCD cameras used realise approx. five million measuring points in an interval of a few seconds. The projector of the measurement head projects the sequence of stripes on the measured object (Fig. 9), while the CCD cameras record their course. By solving the optical transformation equations, the system calculates the coordinates for each camera pixel with high accuracy. The result of a single measurement is a point cloud that unambiguously reflects the scanned surface. The measurement is saved in STL (Standard Triangle Language) format, which needs to be converted into a $3 \mathrm{D}$ project.

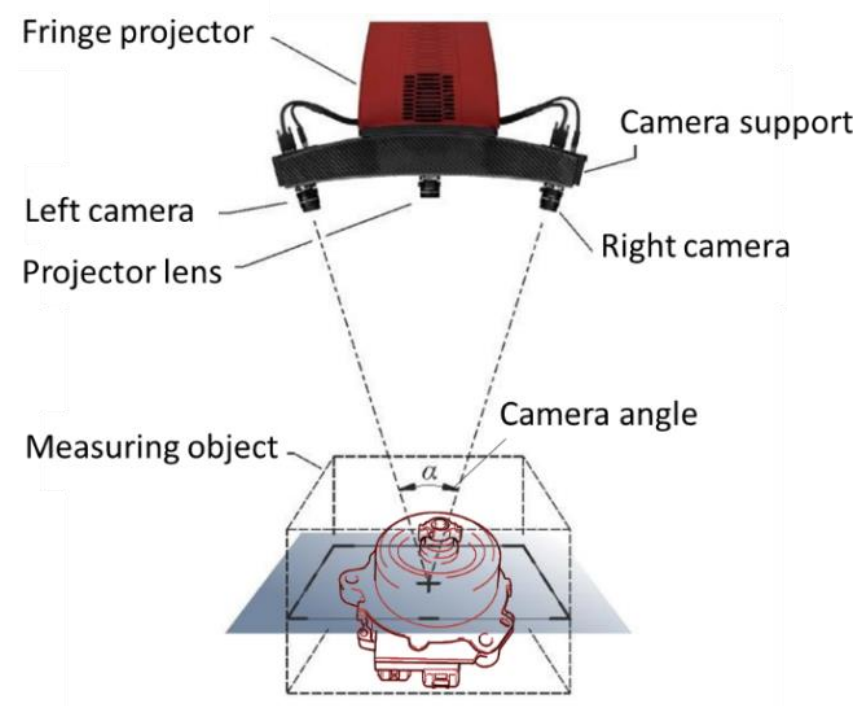

Fig. 7. Scanning process diagram

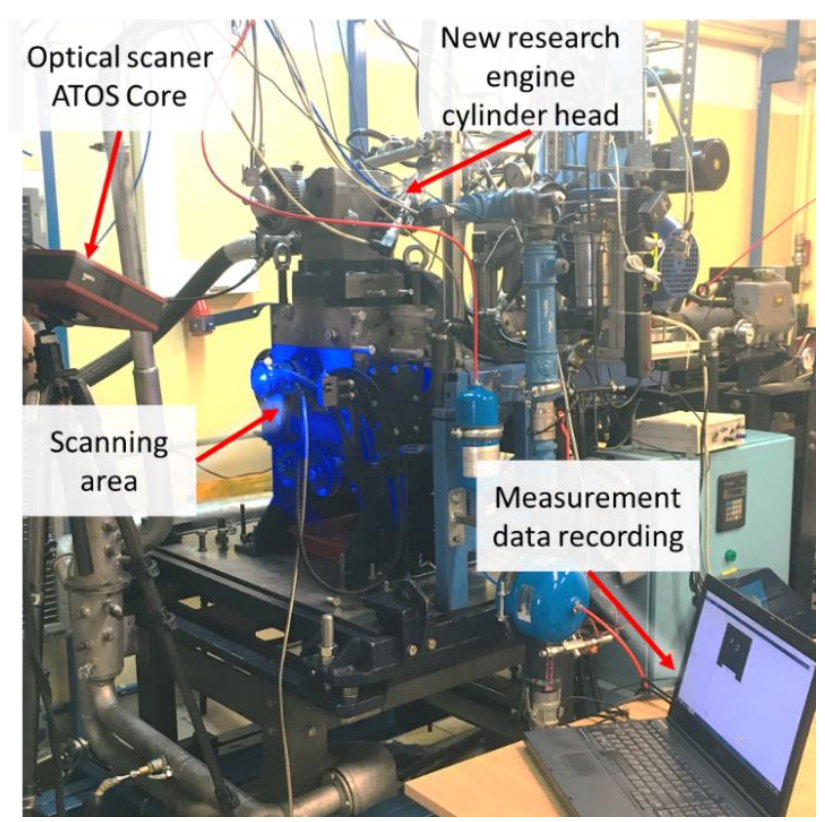

Fig. 8. Optical scanning process of area of driveline

\subsection{Tomographic scanning}

The single cylinder test engine whose cylinder head has been modified is equipped with a closed cooling system. It is possible to control the temperature of the cooling liquid on the test bench. The previous step of optical scanning of the cylinder head does not provide information about the structure's internal spaces, the completion of which is crucial to ensure the correct operation of the system. In order to determine the internal areas of the cooling channels as well as the inlet and outlet channels, a CT scan was performed.

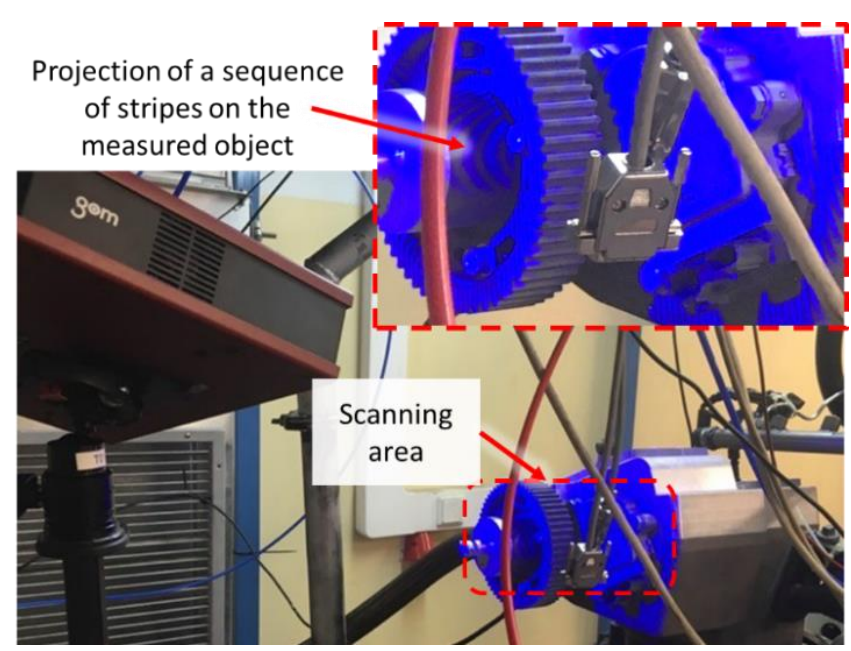

Fig. 9. Projection of a sequence of stripes on the measured object

Computed tomography is one of the noninvasive diagnostic methods to obtain a cross-section through a component. Several tomographic techniques are known [38]:

- x-rays,

- two-dimensional ultrasonography (USG 2D),

- computed tomography(CT),

- magnetic resonance tomography (MRT, NMR - nuclear magnetic resonance),

- positron emission tomography (PET),

- single photon emission tomography (SPECT),

- optical coherent tomography (OCT).

In the diagnostic technique, mainly computed tomography is used to obtain spatial images (3D) while scanning the object from different directions. Figure 10 shows the cylinder head of a GE Phoenix CT scanner. The v/Tome/x m 300 type tomograph with a maximum lamp power of $500 \mathrm{~W}$ with 300 $\mathrm{kV}$ enables high accuracy examinations up to $0.5 \mu \mathrm{m}$ using a $180 \mathrm{kV}$ lamp. Mass of tested elements cannot exceed 50 $\mathrm{kg}$. The maximum dimensions of tested detail are $500 \times 500$ $\times 600 \mathrm{~mm}$.

In order to reconstruct the image, it is necessary to use the analytical method. This method gives the best measurement results but requires large computational capacities. The two-dimensional Fourier analysis method uses a fast Fourier transform to describe the absorption profiles obtained. Each projection is transformed to obtain the absorption coefficient in each voxel. The absorption coefficients are converted into CT numbers, also called Hounsfield HU units [35].

$$
1 \mathrm{HU}=\mathrm{K} \frac{\mu_{\mathrm{p}}-\mu_{\mathrm{w}}}{\mu_{\mathrm{w}}}
$$

where: $\mathrm{K}$ - image gain constant (individual for each CT scanner), $\mu \mathrm{p}-$ pixel absorption coefficient, $\mu \mathrm{w}-$ water absorption coefficient (reference value). 


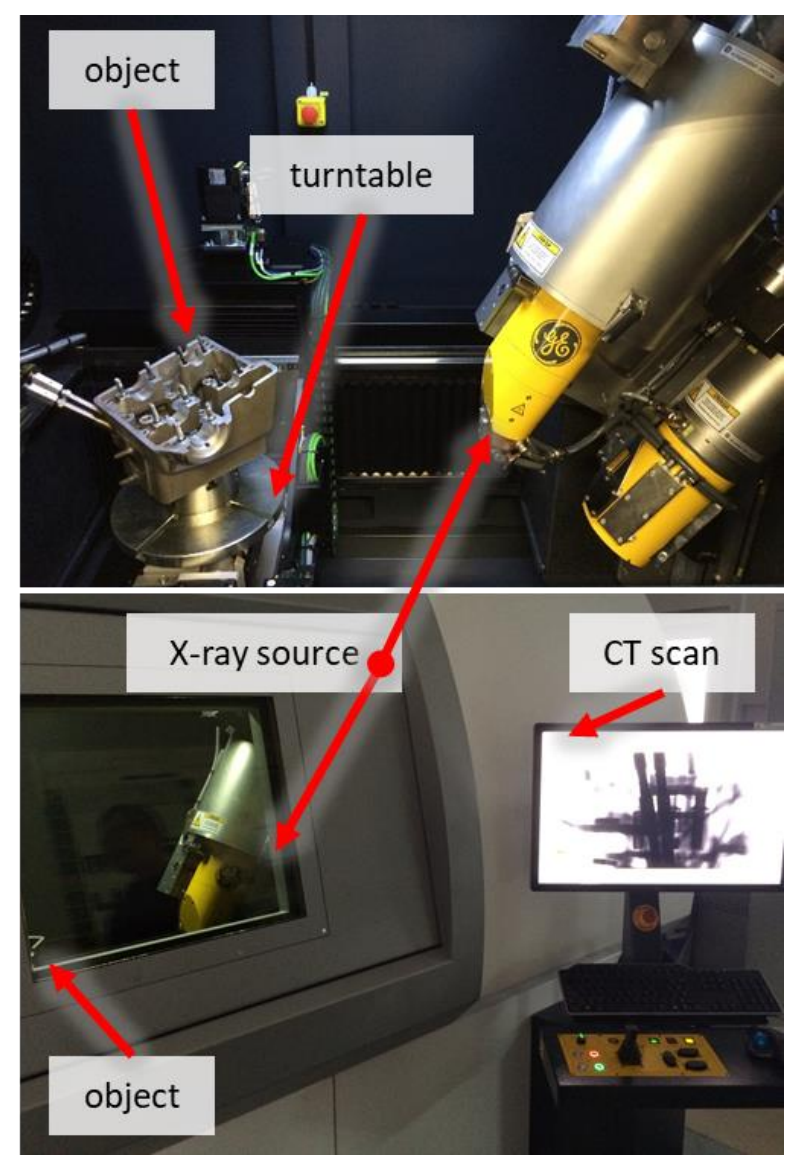

Fig. 10. Location of the research engine head in a GE tomographic scanner model V/Tome/x m

The range of Hounsfield units for CT is -1000 to +4000 , and it allows the image to be represented in shades of grey. Only 256 gray levels are used in practice, which is a selected slice of the CT number value. It makes it possible to observe the image with high contrast, thus enabling the interpretation of the measurement result (Fig. 11).

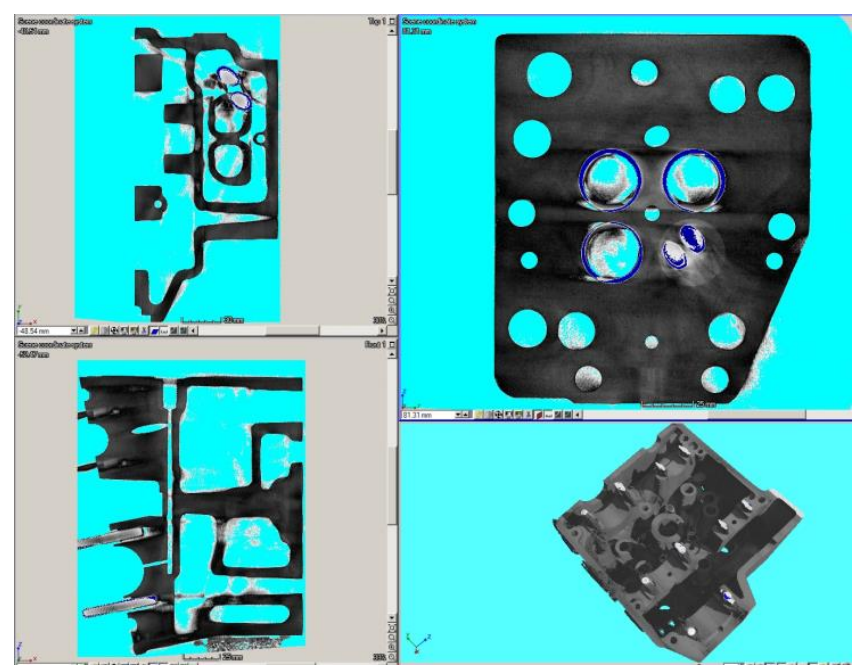

Fig. 11. View of the test engine headspace during tomographic examination

In order to reproduce structural elements, high accuracy of the internal structure of the object is required. To in- crease the measuring accuracy, the method with a linear detector is used (Fig. 10 and 12). This method consists in reducing the radiation beam by means of an aperture to a flat beam. Using a linear detector and rotating $360^{\circ}$, a flat $\mathrm{X}$-ray image of a single slice of the test object is obtained. In order to obtain a spatial image of the entire workpiece, it is necessary to move the object in the vertical plane additionally. During measurements of the cylinder head, the measurement resolution was $2 \mathrm{~mm}$ in the Y-axis, allowing recognition of the geometries necessary for the design of the cylinder head internal volumes (Fig. 13).

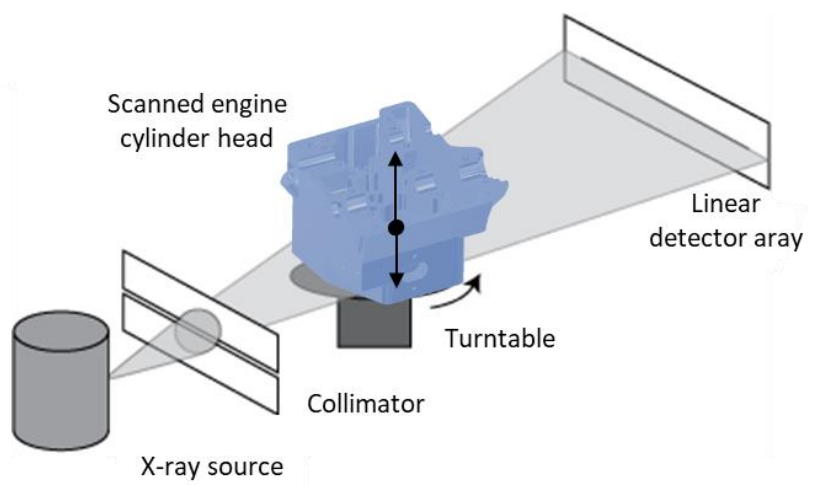

Fig. 12. Methodology tomographic inspection with linear detector

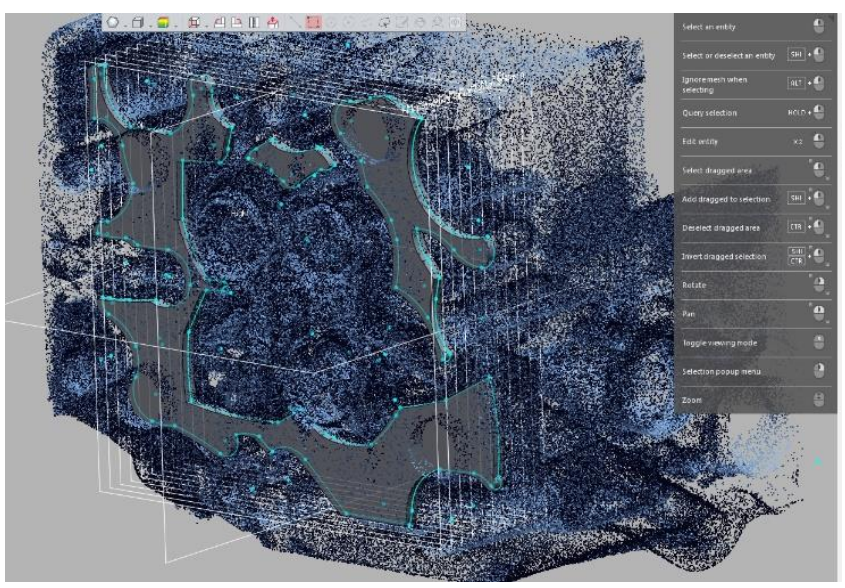

Fig. 13. Design of the internal spaces of the cooling system - view of the measurement point cloud obtained from the tomographic scanning process

\section{Reverse modeling and modernization}

The performed measurements (described in sections 5.1 and 5.2) allowed making a 3D model of the test engine's reference cylinder head. The finished model was compared with the measurement file, and deviations were determined (Fig. 14).

The use of the VVT-iE system resulted in an extension of the cylinder head housing by $99.6 \mathrm{~mm}$ towards the valve train (Fig. 15). As a result, design changes were made to the dry belt drive of the valve train. In order to avoid unfavourable changes in the force distribution on the main bearings of the crankshaft, it was decided to produce an aluminium box equipped with an intermediate shaft (Fig. 16), avoided locating the gear on the extended part of the crankshaft. It could lead to excessive wear of the main sliding bearings and crankshaft fatigue wear. 


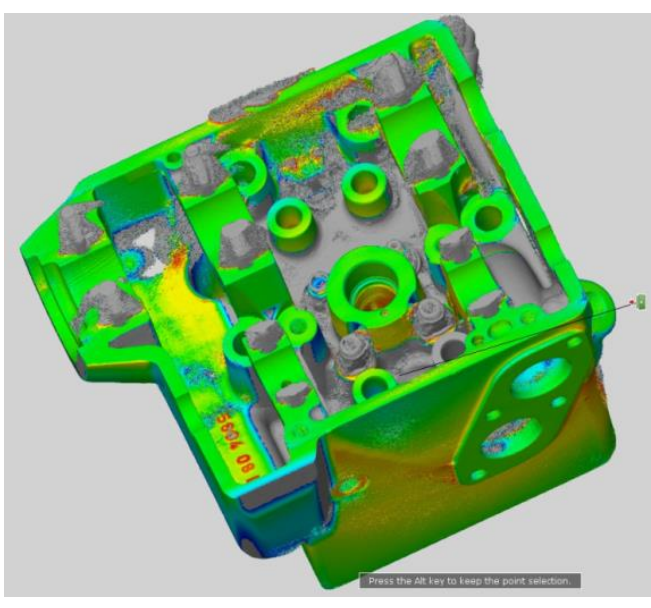

Fig. 14. Comparison of the developed model with the image obtained by scanning along with the specified deviations

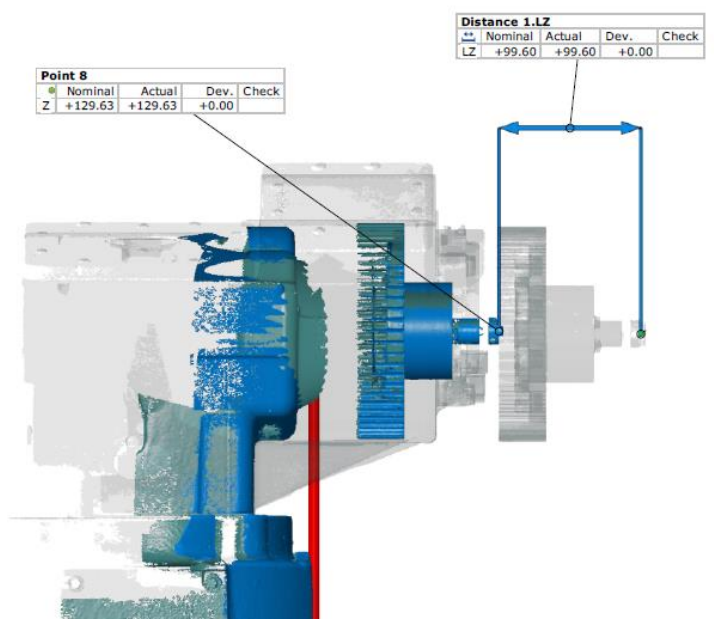

Fig. 15. Visualization of reference and modified cylinder head length comparison based on optical scan results

The design of the new valve train is based on the use of two timing belts instead of one with no change in the timing ratio. Drive is transmitted from crankshaft to intermediate shaft, which in turn drives the exhaust camshaft. The intermediate shaft is supported on both sides by ball roller bearings. Both belts are equipped with an independent tensioning roller system. The view of the intermediate shaft assembled is shown in Fig. 16, and the location on the engine is shown in Fig. 17.

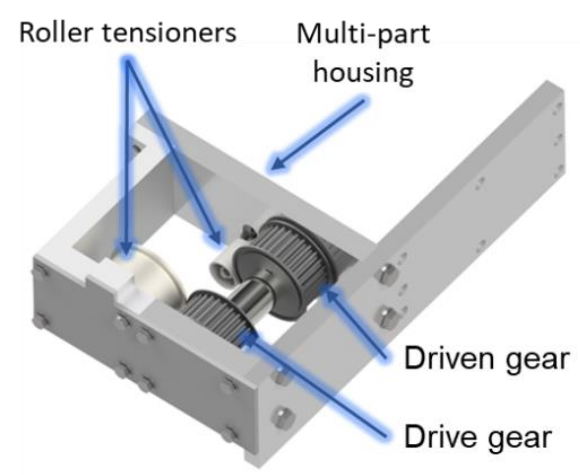

Fig. 16. View of intermediate shaft box

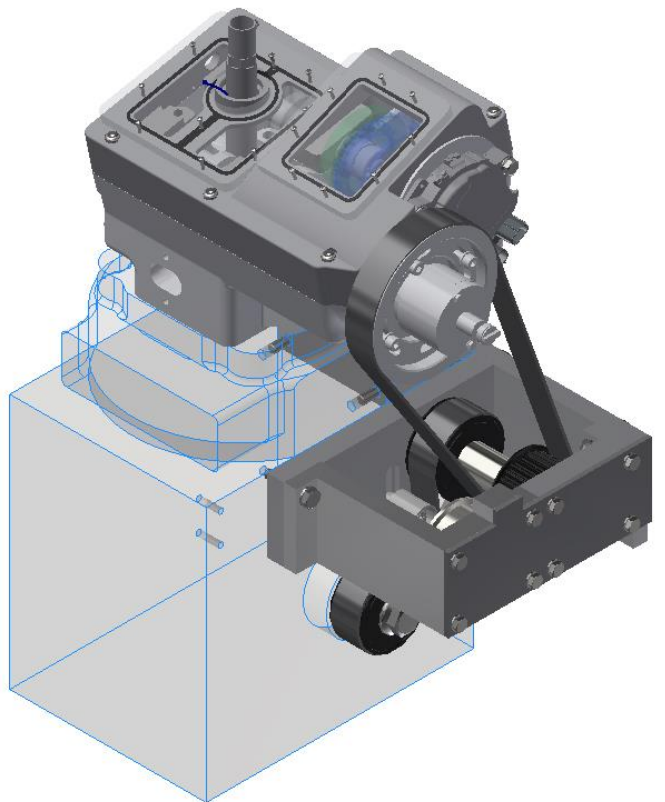

Fig. 17. The CAD model of modified cylinder head and the valve train system

\section{Cylinder head validation and future research steps}

The new components were mounted on a test bench. The cylinder head was subsequently subjected to a leak test. The coolant and oil were forced to flow using an independently controlled AVL 577 system. The fluids were gradually heated up to a temperature of $90^{\circ} \mathrm{C}$.

In the next step of the process, the valve timing diagram was created, taking into account two extreme positions of the intake camshaft (Fig. 18 and 19). The valve timing diagram shows the delay and advanced phase of intake combined with a control range of $47^{\circ} \mathrm{CA}$ and valves opening length of $203^{\circ} \mathrm{CA}$. In addition, the position of the exhaust shaft is fixed. The graph also shows the duration of the opening of the inlet and outlet valves. Moreover, the overlapping duration has been pointed. The opening characteristics of the valves will be individually adjusted at a later stage to the specifics of the tests performed.

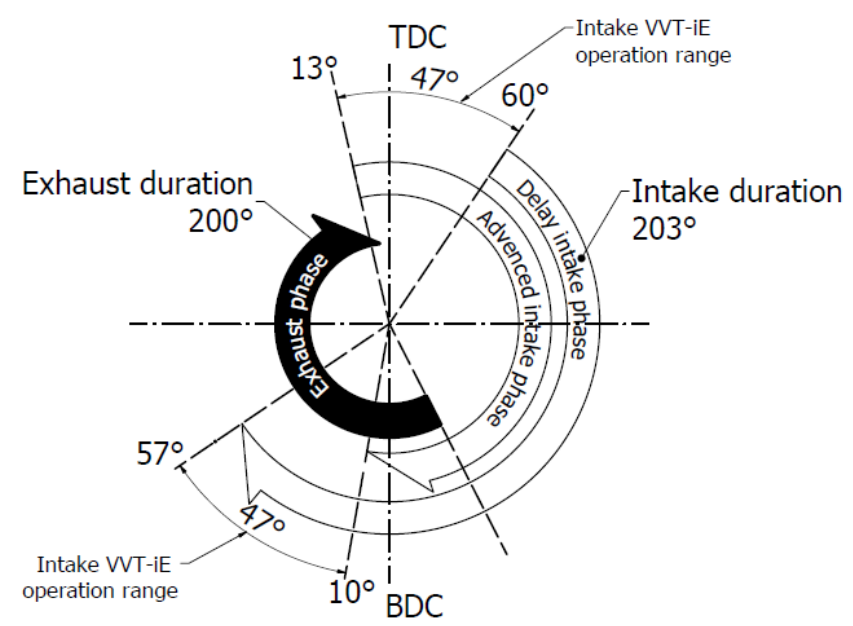

Fig. 18. Valve timing diagram after cylinder head modification 
The last step was to run the engine in motored cycles with a fuel cut. The engine was run at $1500 \mathrm{rpm}$ engine speed, during which the cylinder pressure was recorded for two extreme positions of the intake camshaft (Fig. 19). Position 1 is the maximum intake valve opening advance, while position 2 is the maximum retardation. It resulted in higher peak pressure values for the first intake position due to higher cylinder filling. The readings of the airflow meter located in the intake system per mass of air in the cylinder are $318 \mathrm{mg}$ of air per cycle for position 1 and $302 \mathrm{mg}$ for position 2 . The repeatability of the engine's operation from cycle to cycle is satisfactory in both cases $\operatorname{COV}_{\mathrm{pp}}$ (pp peak pressure) does not exceed $0.3 \%$ of 1000 cycles, which eliminates any irregularities.

The development and implementation of the cylinder head equipped with the described system of electronically controlled valve timing phases allow conducting cycle-bycycle research for precise analysis of transients. Recording the combustion process during a controlled change of the cylinder filling strategy will allow more accurate identification of combustion systems dedicated to hybrid powertrains.

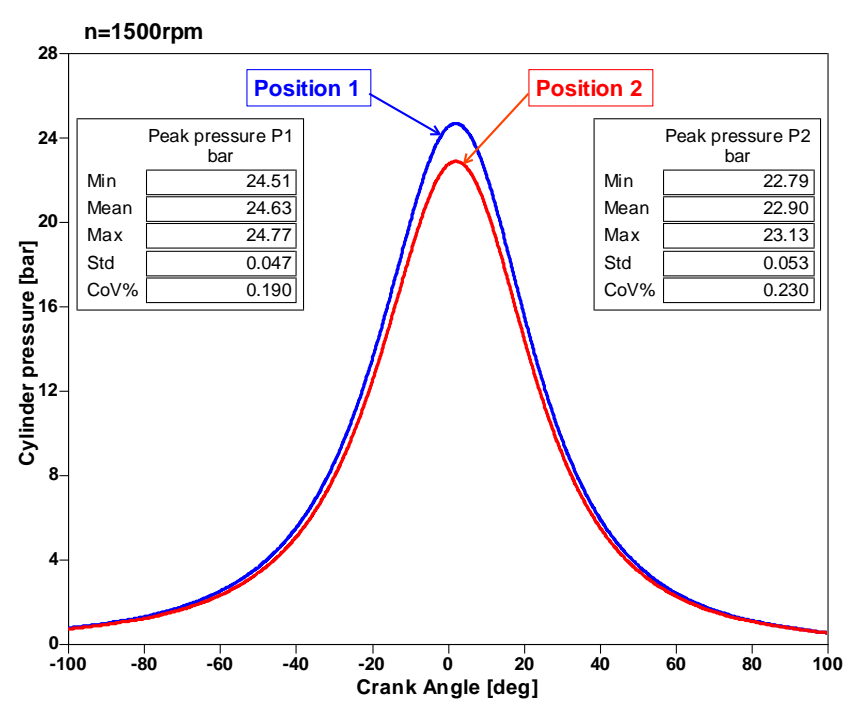

Fig. 19. Cylinder pressure curves for two different intake camshaft modes

Figure 20 shows the waterfall diagram of the cylinder pressure waveform for 15 cycles of engine operation. The position of the inlet camshaft relative to the crankshaft was changed between extreme positions. It should be noted that the repositioning process occurs over several cycles, during which combustion parameters can be monitored.

The content presented in this paper deals with the manufacturing process of an AVL 5804 engine cylinder head modified for research purposes. The manufacturing process included:

- making structural assumptions,

- reconstruction of the original cylinder head geometry using advanced measurement techniques,

- carrying out the design phase,

- manufacture of the cylinder head with equipment,

- starting the modified engine.
The result of the work is a modified engine design that allows research on low-emission combustion systems using the VVT-iE technology. In the future, the test stand will be used for comprehensive analysis of the combustion process and validation of computer simulations, the course of which is presented in Fig. 21.

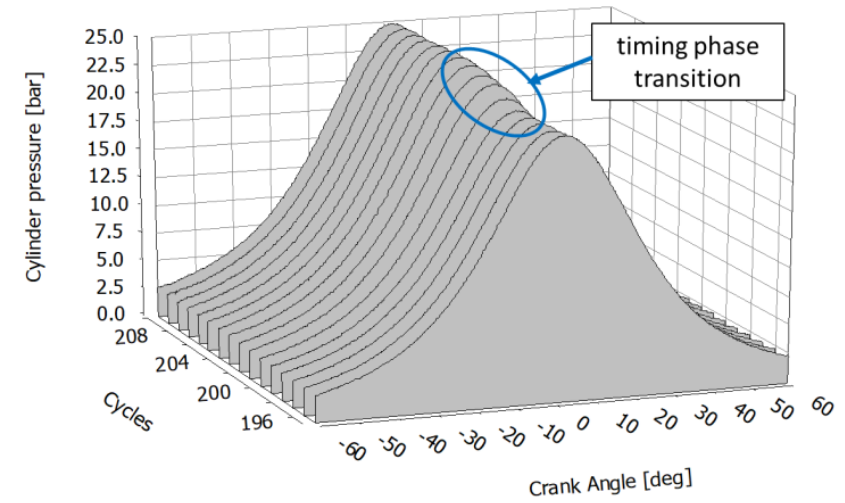

Fig. 20. Waterfall diagram showing the change in compression pressure during changes in the timing system adjustment

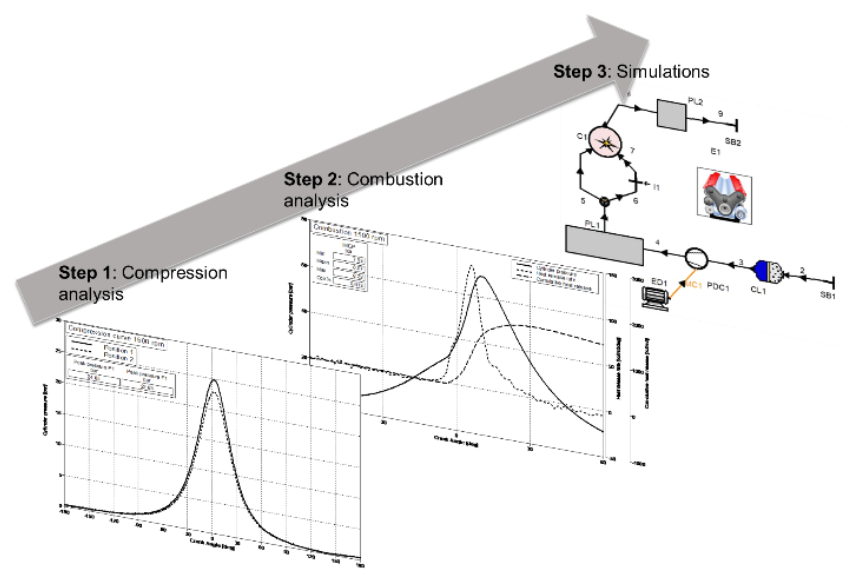

Fig. 21. Graphical representation of the proceedings related to the further development of the test bench.

\section{Conclusion}

The main aims of the performed studies and work described in this paper were to enhance the research possibilities of the 1-cylinder test engine for its operation with variable valve timing and to study the possibilities and restrictions of reverse engineering methodology in modernisation of real engine. Both tasks are successfully fulfilled and completed.

It was proven that $3 \mathrm{D}$-scanning technology makes it possible to generate the fully useful geometrical and constructional project even than when the internal structure of the engine part is very complicated and completely unknown. The generated in this way the construction drawings of cylinder head made it possible to conduct redesigning of it, prepare for the casting process and to final mechanical turning and milling post processing. In this way this methodology has been positively verified.

Finally, the new cylinder head, modernised, equipped with variable valve timing and ready to operate on the 1-cylinder research engine has been delivered, proved and validated. 
The examined methodology of reverse engineering has been proven for cylinder head with very complicated internal structure. This method can be then satisfactory applied in reconstructing of engines or machines parts or elements when the construction documentation is not available and other method of non-destructive recognition of its structure is not available.

\section{Acknowledgements}

This work was supported by the EU - Horizon 2020 [grant number 652816]. The authors of this paper would also like to acknowledge all the people who supported the various stages of designing the prototype cylinder head, especially the employees of the companies and institutions:

- 3D Team - company providing optical scans

- ITWL - Air Force Institute of Technology - cooperation in performing $\mathrm{CT}$ scans

- $4 p$ Engineering Office - the company responsible for the cylinder head casting
- Kazimieruk Precision Parts - company realizing the cylinder head machining

- Świątek - Polish manufacturer of camshafts - maker of prototype camshafts

- FNS Special Tools Factory

- Parawowscy AMP - Engine parts producer - valve manufacturer

- Jacek Tomaszewski - The company responsible for fitting valve seats

\section{Additional information}

Further information and videos from our research are available on YouTube channel: PUT Powertrain Lab

\section{Youtube}
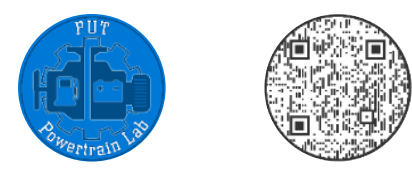

\section{Indexes}

\begin{tabular}{|c|c|c|c|}
\hline BDC & bottom dead center & RCEM & rapid compression expansion machine \\
\hline BMEP & brake mean effective pressure & MCE & multi cylinder engines \\
\hline CAD & computer aided design & OSCE & optical single cylinder engines \\
\hline $\mathrm{CCD}$ & charge-coupled device & PFI & port fuel injection \\
\hline CFD & computational fluid dynamics & SGDI & spray guided direct injection \\
\hline $\mathrm{CT}$ & computed tomography & SI & spark ignition \\
\hline $\mathrm{CoV}$ & coefficient of variation & STL & standard triangle language \\
\hline GHG & greenhouse gas & TJI & turbulent jet ignition \\
\hline $\mathrm{HCCI}$ & homogeneous charge compression ignition & TSCE & thermodynamic single cylinder engine \\
\hline HD & heavy duty & TDC & top dead center \\
\hline ICE & internal combustion engine & VCR & variable compression ratio \\
\hline IMEP & indicated mean effective pressure & VVT-iE & variable valve timing-intelligent electric \\
\hline
\end{tabular}

\section{Bibliography}

[1] SHERRY, C. Internal combustion engine - the road ahead. Efficient Manufacturing. 2019, 10.

https://issuu.com/publishi/docs/em_jan_2019

[2] REITZ, R.D., OGAWA, H., PAYRI, R. et al. IJER Editorial: The future of the internal combustion engine. International Journal of Engine Research. 2020, 21(1), 3-10. https://doi.org/10.1177/1468087419877990

[3] NAPOLITANO, P., FRAIOLI, V., GUIDO, F. et al. Assessment of optimized calibrations in minimizing GHG emissions from a dual fuel $\mathrm{NG} /$ diesel automotive engine. Fuel. 2019, 258, 115997.

https://doi.org/10.1016/j.fuel.2019.115997

[4] ZACHAROF, N., DOULGERIS, S., MYRSINIAS, I. et al A methodology for monitoring on-road $\mathrm{CO}_{2}$ emissions compliance in passenger vehicles. SAE Technical Paper 202037-0034. 2020. https://doi.org/10.4271/2020-37-0034

[5] FRIEDL, H., FRAIDL, G., KAPUS, P. Highest efficiency and ultra low emission - internal combustion engine 4.0. Combustion Engines. 2020, 180(1), 8-16. https://doi.org/10.19206/CE-2020-102

[6] LIU, H., ZHANG, H., SHI, Z. et al. Performance characterization and auto-ignition performance of a rapid compression machine. Energies. 2014, 7, 6083-6104.

https://doi.org/10.3390/en7096083

[7] KYRTATOS, P., BOLLA, M., BENEKOS, S. et al. Advanced methods for gas-prechamber combustion research and model development. 16th Conference The Working Process of the Internal Combustion Engine. Graz 2017.

[8] ELGOWAINY, A., HAN, J., WARD, J. et al. Current and future United States light-duty vehicle pathways: cradle-tograve lifecycle greenhouse gas emissions and economic assessment. Environmental Science \& Technology. 2018, 52(4), 2392-2399. https://doi.org/10.1021/ acs.est.7b06006

[9] JOSHI, A. review of vehicle engine efficiency and emissions. SAE International Journal of Advances and Current Practices in Mobility. 2019, 1(2), 734-761. https://doi.org/10.4271/2019-01-0314

[10] STUHLDREHER, M., KARGUL, J., BARBA, D. et al. Benchmarking a 2016 Honda Civic 1.5-liter L15B7 turbocharged engine and evaluating the future efficiency potential of turbocharged engines. SAE International Journal of Engines. 2018, 11(6), 1273-1305.

https://doi.org/10.4271/2018-01-0319

[11] WISŁOCKI, K. Endoscopic observations of flame propagation in combustion chamber of an DI Diesel engine with mixture partial homogenisation. Combustion Engines. 2007, 128(1), 43-58. https://doi.org/10.19206/CE-117332

[12] PIELECHA, I., WISŁOCKI, K., CIEŚLIK, W. et al. Analysis of a dual-fuel combustion engine fueled with diesel fuel and CNG in transient operating conditions. SAE Technical Paper 2016-01-2305. 2016.

https://doi.org/10.4271/2016-01-2305 
[13] BUESCHKE, W., SZWAJCA, F., WISLOCKI, K. Experimental study on ignitability of lean CNG/air mixture in the multi-stage cascade engine combustion system. SAE Technical Paper 2020-01-2084. 2020.

https://doi.org/10.4271/2020-01-2084

[14] WINKELHOFER, E., HOPFNER, W. Optical single cylinder engines in engine research and development. Combustion Engines. 2013, 152(1), 71-78. https://doi.org/10.19206/CE-117014

[15] MITTAL, M., MEHTA, P. Design features of optically accessible engines for flow and combustion studies - a review. SAE Technical Paper 2018-01-1775. 2018. https://doi.org/10.4271/2018-01-1775

[16] BOWDITCH, F.W. A new tool for combustion research - a quartz piston engine. SAE Technical Paper 610002. 1961. https://doi.org/10.4271/610002

[17] CLASÉN, K., DAHL, A. Development of next generation optical engines concept design and validation by numerical methods. Chalmers University of Technology. Göteborg 2016. https://odr.chalmers.se/bitstream/20.500.12380/247265/1/24 7265.pdf

[18] JOHANSSON, A., DAHLANDER, P. Experimental investigation of the influence of boost on combustion and particulate emissions in optical and metal SGDI-engines operated in stratified mode. SAE International Journal of Engines. 2016, 9(2), 807-818. https://doi.org/10.4271/2016-01-0714

[19] KASHDAN, J., THIROUARD, B. A comparison of combustion and emissions behaviour in optical and metal singlecylinder diesel engines. SAE International Journal of Engines. 2009, 2(1), 1857-1872.

https://doi.org/10.4271/2009-01-1963

[20] RICHMAN, R., REYNOLDS, W. The development of a transparent cylinder engine for piston engine fluid mechanics research. SAE Technical Paper 840379. 1984. https://doi.org/10.4271/840379

[21] KÖGL, R., RUSTLER, M., HIRSCHL, G. New singlecylinder engine generation from AVL. MTZ industrial. 2018, 8, 38-43. https://doi.org/10.1007/s40353-018-0010-0

[22] AVL Single Cylinder Research Engines - AVL product description. Graz 2020.

[23] Ricardo Single-Cylinder Research Engines. Combustion research and mechanical testing of engine parts for diesel, gasoline and alternative fuels.

https://automotive.ricardo.com/engines/single-cylinderresearch-engines

[24] One cylinder, a hundred applications.

https://magazine.fev.com/en/fev-single-cylinder-enginesimportant-development-tools-combustion-optimization/

[25] MENZEL, F., SEIDEL, T., SCHMIDT, W. et al. Singlecylinder engine as a tool for developing new combustion processes. MTZ Worldwide. 2006, 67, 6-9. https://doi.org/10.1007/BF03227827

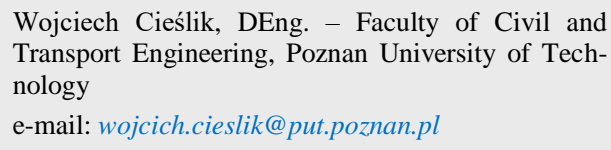
Transport Engineering, Poznan University of Technology e-mail: wojcich.cieslik@put.poznan.pl

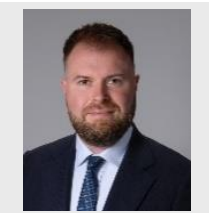

Prof. Krzysztof Wisłocki, DSc., DEng. - Faculty of Civil and Transport Engineering, Poznan University of Technology.

e-mail: krzysz.tof.wislocki@put.poznan.pl
[26] SHI, H., UDDEEN, K., AN, Y. et al. Experimental study on knock mechanism with multiple spark plugs and multiple pressure sensors. SAE Technical Paper 2020-01-2055. 2020. https://doi.org/10.4271/2020-01-2055

[27] MOSER, S., O'DONNELL, R., HOFFMAN, M. et al. Experimental investigation of low cost, low thermal conductivity thermal barrier coating on HCCI combustion, efficiency, and emissions. SAE Technical Paper 2020-01-1140. 2020. https://doi.org/10.4271/2020-01-1140

[28] GRABNER, P., EICHLSEDER, H., ECKHARD, G. Potential of E85 direct injection for passenger car application. SAE Technical Paper 2010-01-2086. 2010. https://doi.org/10.4271/2010-01-2086

[29] SZWAJCA, F., WISŁOCKI, K. Thermodynamic cycles variability of TJI gas engine with different mixture preparation systems. Combustion Engines. 2020, 181(2), 46-52. https://doi.org/10.19206/CE-2020-207

[30] PIELECHA, I., WISŁOCKI, K., CIEŚLIK, W. et al. Application of IMEP and MBF50 indexes for controlling combustion in dual-fuel reciprocating engine. Applied Thermal Engineering. 2018, 132, 188-195. https://doi.org/10.1016/ j.applthermaleng.2017.12.089

[31] HATTORI, M., INOUE, T., MASHIKI, Z. et al. Development of variable valve timing system controlled by electric motor. SAE International Journal of Engines. 2009, 1(1), 985-990. https://doi.org/10.4271/2008-01-1358

[32] BACH, C. Record efficiency for a gas engine. https://www.empa.ch/web/s604/gason

[33] Reactive Flows and Diagnostics. https://www.rsm.tu-darmstadt.de/home_rsm/ members_rsm/members_details_162688.en.jsp

[34] Camshaft control actuator. https://mytechdoc.toyota-europe.com (accessed on 01.03.2020).

[35] BUESCHKE, W., SKOWRON, M., SZWAJCA, F. et al. Flame propagation velocity in 2-stage gas combustion system applied in SI engine. IOP Conference Series: Materials Science and Engineering. 2018, 421. https://doi.org/10.1088/1757-899X/421/4/042009

[36] BUESCHKE, W., SKOWRON, M., WISŁOCKI, K. et al. Comparative study on combustion characteristics of lean premixed $\mathrm{CH}_{4}$ /air mixtures in RCM using spark ignition and turbulent jet ignition in terms of orifices angular position change. Combustion Engines. 2019, 176(1), 36-41. https://doi.org/10.19206/CE-2019-105

[37] Reverse engineering. https://reversesolutions.pl/inzy-nieria-odwrotna/ (accessed on 07.09.2021)

[38] KUŁASZKA, A., CHALIMONIUK, M., WIECZOROWSKI, M. The assessment of defects and discontinuities in weldings by means of computed tomography. Przeglad spawalnictwa. 2015, 87(12). http://www.pspaw.pl/index.php/pspaw/article/view/541/546

Filip Szwajca, MEng. - Faculty of Civil and Transport Engineering, Poznan University of Technology. e-mail: filip.szwajca@put.poznan.pl

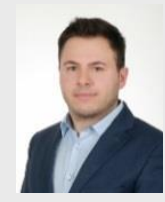

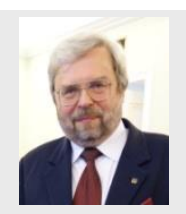

